\title{
XXVII. Notizen.
}

\section{Ferienkurse Jena.}

Vom 3.-16. August 1911. (Für Damen und Herren.)

Es werden in ganzen mehr als 50 verschiedene Kurse gebalten, meist zwölfstündige.

Natnrwissenschaftliche Abteilung: Naturphilosophie; Botanik; botanisch-mikroskopisches Praktikum; Zoologie; zoologisches Praktikum; Astronomie; Geologie; Chemie; Physik; Physiologie; physiologische Psychologie.

Ferner sei anf die pädagogischen, literatargeschichtlichen, religionswissenschaftlichen nnd staatswissenschaftlichen Karse hingewiesen.

Ansführliche Programme sind kostenfrei durch das Sekretariat der Ferienkarse (Jena, Gartenstraße 4) za haben.

\section{Berichtigung.}

In dem Artikel XVII, J. E. Hihsch: Geologische Karte des Bühmischen Mittelgebirges, Blatt VI (Wernstadt-Zinkenstein), sind folgende Koriekturen vorzunehmen:

"Seite 400 , Textfigur 2 , unten links, lies anstatt os richtig os."

„Für die Gesteine sind in Fig. 2 (Seite 400) die gleichen Bezeichnungen angewendet wie in der Karte.

"Seite 405 oben, I. Reihe, lies anstatt Magnetit II richtig JIagnetit I."

"Seite 427 , Zeile 7 von onten, lies anstatt $1.4 \check{0}$ richtig $1.50 .{ }^{\circ}$ 